\title{
Uso da cafeína como indicador de poluição por esgoto doméstico em corpos d’água urbanos
}

\author{
Use of caffeine as an indicator of pollution \\ by domestic sewage in urban water bodies \\ João Miguel Merces Bega'* ${ }^{\circ}$, Jefferson Nascimento de Oliveira' ${ }^{\oplus}$, \\ Liliane Lazzari Albertin' ${ }^{\oplus}$, William Deodato Isique ${ }^{1}(\mathbb{0}$
}

\begin{abstract}
RESUMO
Nos centros populacionais, os ambientes aquáticos estão em constante degradação em consequência das atividades desenvolvidas nas bacias de drenagem, sendo o despejo de esgoto doméstico uma das maiores fontes de poluição. Monitoramentos ambientais de qualidade da água refletem os poluentes gerados nas áreas de influência e dão indícios das prováveis origens. Todavia, são as substâncias de uso exclusivamente antrópico que podem comprovar a existência do lançamento de tais cargas poluidoras. Nesse contexto, o presente trabalho teve como objetivo avaliar a eficiência da cafeína como indicador de poluição por esgoto doméstico. O método analítico utilizado para a sua identificação foi a cromatografia líquida de alta eficiência. Com o intuito de relacionar os resultados obtidos para a cafeína com a diluição e as fontes difusas de poluição, foram aferidos, ainda, dados de precipitação, oxigênio dissolvido e demanda bioquímica de oxigênio. A cafeína foi encontrada em todas as amostras analisadas, com concentrações variando de 0,01 a 7,80 mg.L"1. Os maiores valores foram observados no período chuvoso, relacionados ao transbordamento e ao vazamento de esgoto doméstico. Este estudo inferiu a utilização da cafeína como eficiente indicador de poluição por esgoto doméstico. Palavras-chave: compostos emergentes; degradação ambiental; poluição difusa; áreas urbanas.
\end{abstract}

\begin{abstract}
In population centers, aquatic environments are in constant degradation due to the activities carried out in watersheds, with the release of domestic sewage being one of the biggest sources of pollution. Environmental monitoring of water quality reflects the inputs generated in the areas of influence and gives evidence of likely origins. However, it is the substances for exclusively anthropic use that can prove the existence of the release of such polluting loads. In this context, the present study aimed to evaluate the efficiency of caffeine as an indicator of pollution by domestic sewage. The analytical method used for its identification was high-performance liquid chromatography (HPLC). In order to relate the results obtained for caffeine with the dilution and nonpoint sources pollution, data on precipitation, dissolved oxygen, and biochemical oxygen demand were also measured. Caffeine was found in all samples analyzed, with concentrations ranging from 0.01 to $7.80 \mathrm{mg} \mathrm{L}^{-1}$. The highest values were observed in the rainy season, related to the overflow and leakage of domestic sewage. This study infered the use of caffeine as an efficient indicator of pollution by domestic sewage.
\end{abstract}

Keywords: emerging compounds; environmental degradation; nonpoint source pollution; urban areas.

\section{INTRODUÇÃO}

O crescimento desordenado das cidades, caracterizado pelo aumento exponencial da população e pela expansão não planejada da malha urbana, corrobora para a degradação dos recursos naturais. Os ecossistemas aquáticos são afetados pelo processo de urbanização. As mudanças no uso e ocupação do solo (e.g., retirada de matas ciliares e substituição da vegetação por superfícies impermeáveis) e as práticas desenvolvidas nas bacias de drenagem podem levar ao decréscimo da qualidade de suas águas (ESPEJO et al., 2012; FIA et al., 2015; LIU; BRALTS;
ENGEL, 2015). Ademais, uma oscilação temporal na qualidade da água pode refletir as formas de cobertura do solo de uma região (KALSCHEUR et al., 2012). Muitos artigos têm sido publicados sobre a degradação da qualidade das águas superficiais em razão das influências antropogênicas nas bacias hidrográficas, demonstrando a importância da quantificação dos poluentes carreados, assim como suas concentrações no ambiente (TONG; CHEN, 2002; ROSEMOND; DURO; DUBÉ, 2009; ORTEGA; CARVALHO, 2013; MENEZES et al., 2016; ZAMBRANO; POLETO; OLIVEIRA, 2017).

"Faculdade de Engenharia de Ilha Solteira, Universidade Estadual Paulista "Júlio de Mesquita Filho" - Ilha Solteira (SP), Brasil.

*Autor correspondente: joaomiguelbega@gmail.com

Conflitos de interesse: os autores declaram não haver conflito de interesses.

Financiamento: Coordenação de Aperfeiçoamento de Pessoal de Nível Superior (CAPES) e Conselho Nacional de Desenvolvimento Científico e Tecnológico (CNPq) Recebido: 18/03/2019 - Aceito: 31/03/2020 - Reg. ABES: 20190084 
Nas duas últimas décadas, novas substâncias químicas e não regulamentadas (e.g., compostos emergentes) têm ganhado destaque no meio científico e sido amplamente utilizadas em monitoramentos de qualidade da água, uma vez que muitas delas são de uso exclusivamente antrópico, por exemplo, a cafeína (BUERGE et al., 2003; FERREIRA; CUNHA, 2005; SAUVÉ et al., 2012; IDE et al., 2013; LORENZO et al., 2019). A presença da cafeína nos rios e nos córregos pode representar a existência de lançamentos de esgoto doméstico in natura, sobretudo em área urbana (FERREIRA, 2005; IDE et al., 2013). No mais, com a sua aplicação é possível, também, obter informações sobre o comportamento dos cidadãos (e.g., menor consumo de café aos finais de semana) e estimar a população flutuante de localidades que recebem grande quantidade de turistas (i.e., pela variação temporal das concentrações de cafeína em estações de tratamento de esgoto - ETEs e cursos d'água) (SENTA et al., 2015).

A cafeína é o principal ingrediente estimulante utilizado no café, sendo também encontrada em chás e bebidas energéticas. Quando consumida em diferentes produtos, a sua maior parte é metabolizada em teofilina, teobromina, paraxantina e ácido 1,3,7-trimetilúrico (REGAL et al., 1998). Apenas uma pequena parcela (0,5-10\%) permanece intacta após ser excretada (BUERGE et al., 2003), especialmente na forma de urina, que acaba chegando ao sistema de esgotamento sanitário (HUKKANEN; JACOB; BENOWITZ, 2005). Peeler (2004) verificou que a cafeína se decompõe sob condições naturais (e.g., exposição à radiação solar), podendo a taxa de decaimento ser reduzida pela proteção da luz e pela refrigeração. Por fim, a autora concluiu que a sua taxa de meia-vida de 30 dias, aferida em uma amostra de água natural sujeita a condições naturais, suporta o seu uso como indicador de fonte de poluição.

A Sub-bacia do Córrego Sem Nome, localizada no município de Ilha Solteira, São Paulo, encontra-se inteiramente inserida no perímetro urbano e conta com a nascente do córrego Sem Nome. Poleto (2003), Ortega e Carvalho (2013) e Zambrano et al. (2017) demonstraram a piora na qualidade da água do córrego no período de 2002 a 2016. Além disso, eles apontaram o lançamento de esgoto doméstico in natura como fator responsável por essa situação, decorrente dos altos teores de demanda bioquímica de oxigênio (DBO) e das baixas concentrações de oxigênio dissolvido (OD) encontradas. Isso posto, o presente estudo teve como objetivos: avaliar as variabilidades espacial e temporal da concentração de cafeína no córrego Sem Nome, para detectar a presença ou a ausência de esgoto doméstico, e comparar os resultados obtidos com eventos de precipitação e teores de DBO e de OD, tendo o intuito de inferir se a cafeína é um bom indicador de poluição por esgoto doméstico.

\section{METODOLOGIA}

A área de estudo está localizada na cidade de Ilha Solteira, noroeste do estado de São Paulo, entre as coordenadas geográficas: longitude oeste $51^{\circ} 06^{\prime} 35^{\prime \prime}$ e latitude sul $20^{\circ} 38^{\prime} 44^{\prime \prime}$. No último censo, de 2010 (IBGE, 2010), o município apresentou cerca de 25 mil habitantes, com aproximadamente 24 mil vivendo em área urbana. Os tipos de solo encontrados na região são argilosos vermelho-amarelos e latossolos vermelhos. O relevo caracteriza-se por colinas médias e amplas (SANTIM, 2010). Segundo a classificação climática de Köppen, o clima local é semiúmido, Aw, marcado por estiagem no inverno e chuvas intensas no verão, com índice pluviométrico de $1.300 \mathrm{~mm}$ por ano e temperatura média de $23,6^{\circ} \mathrm{C}$ (ALVARES et al., 2013).

A Sub-bacia do Córrego Sem Nome (Figura 1) abrange $80 \%$ da área territorial urbana de Ilha Solteira $\left(3,47 \mathrm{~km}^{2}\right)$. Apesar de haver rede coletora no local de estudo, Ortega e Carvalho (2013) e Zambrano et al. (2017) relataram a possibilidade de algumas residências contarem com ligações clandestinas (i.e., ligação do ramal predial de esgotos no ramal predial de drenagem pluvial). No que lhe concerne, o córrego Sem Nome recebe todo o escoamento superficial pluvial gerado na sub-bacia. Os dois pontos de amostragem (P1 e P2) (Figura 1), distantes $300 \mathrm{~m}$, foram escolhidos por serem representativos quanto à qualidade da água, considerando os resultados obtidos por Poleto (2003), Ortega e Carvalho (2013) e Zambrano et al. (2017). Nessas localidades, a água do córrego apresenta odor característico da existência de esgoto doméstico no meio. O ponto de montante (P1) (longitude oeste $51^{\circ} 20^{\prime} 06^{\prime \prime} \mathrm{e}$ latitude sul $\left.20^{\circ} 25^{\prime} 59^{\prime \prime}\right)$ recebe $50 \%$ da contribuição da sub-bacia $\left(1,74 \mathrm{~km}^{2}\right)$. Por sua parte, o de jusante (P2) (longitude oeste $51^{\circ} 20^{\prime} 03^{\prime \prime}$ e latitude sul $\left.20^{\circ} 25^{\prime} 59^{\prime \prime}\right), 60 \%\left(2,24 \mathrm{~km}^{2}\right)$

A metodologia adotada na coleta seguiu o que está descrito no Guia nacional de coleta e preservação das amostras: água, sedimentos, comunidades aquáticas e efluentes líquidos (CETESB, 2011). Foram analisados os parâmetros $\mathrm{OD}$ e DBO, de acordo com o Standard methods for the examination of water and wastewater (APHA, 2017), além do composto emergente cafeína. As análises foram conduzidas no Laboratório de Saneamento da Faculdade de Engenharia de Ilha Solteira da Universidade Estadual Paulista "Júlio de Mesquita Filho" (FEIS/UNESP). A amostragem foi realizada mensalmente, sempre às 8,14 e 19h, buscando avaliar a variação diária dos parâmetros estudados. O período de monitoramento foi de seis meses, entre dezembro de 2017 e junho de 2018.

$\mathrm{Na}$ identificação da cafeína, foi usado um cromatógrafo líquido de alta eficiência (Shimadzu), provido de duas bombas (LC-20AT e LC-20AD), um injetor Rheodyne (Rohnert Park, CA, USA), munido com uma válvula do tipo loop de $20 \mathrm{~mL}$, e um detector SPD-M20A (Prominence Diode Array Detector) (comprimento de onda: $222 \mathrm{~nm}$ ), contendo o software LCsolution. A coluna cromatográfica empregada foi a Column Zorbax ODS C18 (150 × 4,6 mm ID, partículas de $5 \mu \mathrm{m}$ ). Para a preparação das amostras de cafeína, foi utilizada a microextração líquido-líquido dispersiva (DLLME). Essa técnica apresenta as seguintes vantagens: simplicidade de operação, baixo custo, rapidez e alta eficiência de extração. O procedimento foi realizado de acordo com o método proposto por Martins et al. (2012):

- Em tubos de ensaio do tipo cônico, contendo $25 \mathrm{mg}$ de cloreto de sódio $(\mathrm{NaCl})$, foram adicionados $5 \mathrm{~mL}$ de amostras de água do córrego Sem Nome;

- Os tubos foram submetidos ao vórtex (agitação por três minutos para a diluição do $\mathrm{NaCl}$ );

- Posteriormente, foram adicionados $500 \mu \mathrm{L}$ de metanol (agente dispersor) e $500 \mu \mathrm{L}$ de tetracloreto de carbono (agente extrator);

- Novamente, os tubos foram submetidos ao vórtex por três minutos;

- Foi realizada a centrifugação dos tubos cônicos por 3 minutos a 3.500 rpm;

- Com o auxílio de uma microsseringa de $100 \mu \mathrm{L}$, a fração orgânica (contendo a cafeína) foi transferida de cada amostra para tubos de ensaio devidamente etiquetados; 
- Os tubos de ensaio foram colocados em um bloco digestor para secagem a $50^{\circ} \mathrm{C}$;

- O material contido nas amostras foi ressuspendido com $300 \mu \mathrm{L}$ de metanol;

- Por fim, $25 \mu \mathrm{L}$ da amostra foram injetados no cromatógrafo líquido.

A eluição por gradiente é aplicada na separação cromatográfica com a função de aumentar a força da fase móvel, sobretudo quando dois solutos possuem variedade de fatores de retenção $(\mathrm{k})$. Os gradientes utilizados para as análises de cafeína (SRDJENOVIC et al., 2008) estão demonstrados na Tabela 1.

O método utilizado para elaborar a curva analítica da cafeína foi o da junção entre os limites de detecção (LD) (0,055 $\left.\mu \mathrm{g} . \mathrm{L}^{-1}\right)$ e os limites de quantificação (LQ) $\left(0,170 \mu \mathrm{g} . \mathrm{L}^{-1}\right)$ (AMÉRICO, 2010). Ela foi efetuada por meio da diluição (proporção de 1:1) de uma solução de $100 \mathrm{mg} \cdot \mathrm{L}^{-1}$, obtendo-se as seguintes concentrações: 50, 25, 12,5 e 6,25 mg. $\mathrm{L}^{-1}$ (coeficiente de determinação $-\mathrm{R}^{2}=0,9972$ ).

A precipitação que ocorre no dia da coleta e em dias anteriores pode influenciar a qualidade da água, consequentemente os valores encontrados para os parâmetros físicos, químicos e biológicos. Dessa forma, foram levantados dados pluviométricos referentes aos meses de monitoramento na área de estudo, retirados do site da Área de Hidráulica e Irrigação do Departamento de Fitossanidade, Engenharia Rural e Solos e da estação pluviométrica do Laboratório de Hidrologia e Hidrometria, ambos vinculados à FEIS/UNESP.

\section{RESULTADOS E DISCUSSÃO}

Para melhor compreensão e organização dos resultados, adotou-se a seguinte nomenclatura:

- 1 e 2: pontos P1 e P2, respectivamente;

- A, B e C: manhã, tarde e noite, respectivamente.

\begin{tabular}{l|c|c}
\multirow{2}{*}{ Tabela 1 - Gradientes de eluição para a cafeína. } \\
\cline { 2 - 3 } & \multicolumn{2}{|c}{ Cafeina } \\
\hline \multirow{2}{*}{$\mathrm{MeOH}$} & Tempo (minuto) & Fase móvel \\
\hline $\mathrm{H}_{2} \mathrm{O}$ Milli-Q & 0,01 & 10 \\
\hline $\mathrm{MeOH}$ & 0,01 & 90 \\
\hline $\mathrm{H}_{2} \mathrm{O}$ Milli-Q & 8 & 90 \\
\hline $\mathrm{MeOH}$ & 8 & 10 \\
\hline $\mathrm{H}_{2} \mathrm{O}$ Milli-Q & 9 & 90 \\
\hline $\mathrm{MeOH}$ & 9 & 10 \\
\hline $\mathrm{H}_{2} \mathrm{O}$ Milli-Q & 10 & 10 \\
\hline $\mathrm{MeOH}$ & 10 & 90 \\
\hline
\end{tabular}

$\mathrm{H}_{2} \mathrm{O}$ Milli-Q acidificada com ácido trifluoracético (O,O1 \% v/v); MeOH: metanol.



Figura 1 - Sub-bacia do Córrego Sem Nome e localização dos pontos de amostragem. 
Logo, o índice 1A, por exemplo, refere-se à concentração da variável obtida no ponto $\mathrm{P} 1$, no período da manhã.

Os valores encontrados de DBO e de OD estão apresentados na Tabela 2. Altos teores de DBO e baixas concentrações de OD foram aferidas, refletindo as más práticas antrópicas desenvolvidas na Sub-bacia do Córrego Sem Nome. Infere-se como causa principal a existência de aporte de matéria orgânica por meio de possíveis lançamentos clandestinos de esgoto doméstico, corroborando para a degradação da qualidade da água do córrego.

As maiores concentrações de OD foram observadas no ponto P1, mesmo este tendo apresentado os maiores teores de $\mathrm{DBO}$, em razão, entre outros fatores, da velocidade do fluido, do volume do corpo d'água, da lâmina do canal, da incidência de radiação solar e da turbulência do escoamento (MANDAL et al., 2012; SALLAM; ELSAYED, 2018). Todos esses fatores levaram aos resultados verificados, por mais que a poluição por matéria orgânica seja mais intensa no P1. Quanto às variações diárias, no ponto P2, os maiores valores de OD foram obtidos no período da tarde, o que também foi relatado por Zambrano et al. (2017) entre os anos de 2015 e 2016. Em relação ao ponto $\mathrm{P} 1$, as concentrações mais altas foram encontradas no período da noite, o que reflete a baixa influência das atividades fotossintéticas no local, dado que a noite as plantas não realizam fotossíntese, diminuindo a disponibilidade de oxigênio na água. Foi aferida, ainda, a concentração de $0 \mathrm{mg} \cdot \mathrm{L}^{-1}$. O oxigênio desempenha papel vital na saúde ecológica dos ecossistemas aquáticos, sendo a sua presença necessária para a manutenção dos organismos aeróbios (MADER et al., 2017). Além disso, quando em baixas concentrações, pode levar à mortalidade de peixes (BANERJEE et al., 2019). Acerca da DBO, os maiores teores foram observados no período da tarde em ambos os pontos de amostragem, indicando uma contribuição de matéria orgânica elevada após o almoço e, possivelmente, um hábito da população da Sub-bacia do Córrego Sem Nome relacionado às atividades fisiológicas. Da comparação dos pontos amostrais, os valores obtidos de DBO foram maiores no ponto P1. Portanto, pelo canal apresentar maior volume de água no ponto P2, a diluição acaba minimizando o efeito da poluição.

O córrego Sem Nome não se encontra enquadrado no licenciamento ambiental dos corpos hídricos superficiais. A classe 2 foi adotada em função dos usos preponderantes mais exigentes. O limite estabelecido pela Resolução do Conselho Nacional do Meio Ambiente (CONAMA) $n^{\circ} 357 / 05$ (BRASIL, 2005) para a DBO (superior) e para o OD (inferior) é de $5 \mathrm{mg} . \mathrm{L}^{-1}$. Somente $8 \%$ das concentrações de OD atenderam ao estabelecido pela legislação. Por sua parte, para a DBO, apenas $3 \%$. Houve decréscimo na concentração de OD nas águas do córrego ao longo das duas últimas décadas. Poleto (2003) e Ortega e Carvalho (2013) encontraram valores, em média, $170 \%$ maiores que os apresentados neste trabalho. Por outro lado, Zambrano et al. (2017) aferiram concentrações similares. Foi verificado que a falta de conscientização ambiental por parte da população, as práticas incorretas de manejo do uso e ocupação do solo, a carência de manutenção de obras de drenagem pluvial, a ausência de coleta de resíduos orgânicos diária e o desmatamento de parte da vegetação ripária são fatores que vêm influenciando negativamente com o passar dos anos.

Conforme reforçou Poleto (2003), as precipitações que ocorrem até três dias antes da coleta influenciam significativamente a qualidade da água. A Tabela 3 apresenta a altura pluviométrica precipitada nos dias de interesse.

Nos meses de março, maio e junho de 2018, sem precipitação na proximidade do dia de amostragem, os valores de DBO foram maiores quando comparados aos meses chuvosos (dezembro de 2017 e janeiro e fevereiro de 2018). As concentrações de OD apresentaram comportamento oposto. De fato, o lançamento de esgoto doméstico in natura pode ser o responsável pela elevada

Tabela 3 - Precipitações nos dias de coleta das amostras e nos três dias anteriores. \begin{tabular}{|l|l|l|l|l} 
Mês de amostragem & $\mathrm{dO}(\mathrm{mm})$ & $\mathrm{d} 1(\mathrm{~mm})$ & $\mathrm{d} 2(\mathrm{~mm})$ & $\mathrm{d} 3(\mathrm{~mm})$
\end{tabular}

\begin{tabular}{l|c|c|c|c}
\hline $12 / 2017$ & $0,5^{*}$ & 20,3 & 0 & 36,6 \\
\hline $01 / 2018$ & $2,5^{* *}$ & 0,5 & 0 & 11,7 \\
\hline $02 / 2018$ & $2,5^{*}$ & 2,8 & 0 & 0,5 \\
\hline $03 / 2018$ & 0 & 0 & 0 & 0 \\
\hline $05 / 2018$ & 0 & 0 & 0 & 0 \\
\hline $06 / 2018$ & 0 & 0 & 0 & 0 \\
\hline
\end{tabular}

dO: precipitação ocorrida no dia da amostragem; d1, d2 e d3: precipitações ocorridas um, dois e três dias antes da amostragem; *antes do período da manhã; **antes do período da tarde.

Tabela 2 - Variações espacial e temporal da concentração de oxigênio dissolvido e do teor de demanda bioquímica de oxigênio no córrego Sem Nome.

\begin{tabular}{|c|c|c|c|c|c|c|c|c|c|c|c|c|}
\hline & \multicolumn{6}{|c|}{$\mathrm{OD}\left(\mathrm{mg} \cdot \mathrm{L}^{-1}\right)$} & \multicolumn{6}{|c|}{$\mathrm{DBO}\left(\mathrm{mg} \cdot \mathrm{L}^{-1}\right)$} \\
\hline & $1 \mathrm{~A}$ & $2 \mathrm{~A}$ & $1 \mathrm{~B}$ & $2 \mathrm{~B}$ & $1 \mathrm{C}$ & $2 \mathrm{C}$ & $1 \mathrm{~A}$ & $2 \mathrm{~A}$ & 1B & $2 \mathrm{~B}$ & $1 \mathrm{C}$ & $2 \mathrm{C}$ \\
\hline $12 / 2017$ & 4,05 & 3,45 & 5,27 & 3,55 & 5,37 & 2,94 & 81,07 & 10,13 & 70,94 & 13,17 & 91,21 & 13,19 \\
\hline 01/2018 & 2,94 & 1,82 & 2,43 & 2,63 & 4,16 & 2,53 & 45,55 & 14,19 & 45,60 & 28,36 & 70,93 & 12,16 \\
\hline $02 / 2018$ & 2,74 & 4,16 & 2,74 & 2,94 & 4,56 & 1,62 & 4,11 & 10,13 & 64,86 & 32,42 & 12,08 & 23,31 \\
\hline $03 / 2018$ & 2,74 & 0,81 & 1,32 & 0,20 & 1,52 & 0,00 & 115,50 & 41,55 & 127,64 & 53,73 & 66,88 & 60,81 \\
\hline 05/2018 & 1,72 & 0,61 & 2,13 & 2,03 & 3,24 & 1,01 & 20,29 & 25,34 & 55,79 & 25,35 & 5,07 & 6,09 \\
\hline $06 / 2018$ & 2,23 & 6,49 & 4,05 & 4,26 & 3,75 & 0,41 & 123,66 & 12,15 & 70,95 & 18,24 & 51,94 & 9,14 \\
\hline
\end{tabular}

OD: oxigênio dissolvido; DBO: demanda bioquímica de oxigênio. 
quantidade de matéria orgânica encontrada. Ademais, os poluentes gerados na superfície da Sub-bacia do Córrego Sem Nome, carreados por meio do escoamento superficial pluvial (i.e., poluição difusa), exercem pouca contribuição para a degradação do córrego, posto que a precipitação proporcionou a melhora na qualidade de suas águas (i.e., caráter diluidor), levando em consideração apenas os parâmetros analisados.

Os perfis cromatográficos constituem os resultados da análise cromatográfica e possibilitam identificar e quantificar os picos cromatográficos de fármacos, cafeína e outros compostos, orgânicos ou não, presentes nas amostras. A confirmação dos compostos orgânicos somente pode ser realizada por meio do seu perfil espectrofotométrico. Os perfis cromatográfico e espectrofotométrico para a cafeína, obtidos pela cromatografia qualitativa em amostras do córrego Sem Nome, encontram-se nas Figuras 2A e $2 \mathrm{~B}$, respectivamente.
As concentrações de cafeína obtidas nos pontos P1 e P2 estão apresentadas nas Figuras 3 e 4, respectivamente. A cafeína foi identificada em todas as amostras, confirmando a existência de lançamentos de esgoto doméstico in natura no córrego. Os maiores valores foram observados nos meses de dezembro de 2017 e janeiro e fevereiro de 2018, referentes ao período de férias escolares. Consequentemente, os efluentes domésticos gerados são maiores, visto que a permanência das pessoas em estabelecimentos públicos e empresariais diminui. Esses possuem rígida fiscalização, dificultando a instalação de ligações clandestinas. Além disso, os meses supracitados correspondem ao período chuvoso (Tabela 2). Os valores encontrados em dezembro de 2017 foram maiores que os identificados nos meses subsequentes, inferindo a ocorrência de vazamento e transbordamento de esgoto doméstico. Sankararamakrishnan e Guo (2005) relataram que as concentrações de cafeína aumentaram na saída de emissários de drenagem pluvial no percurso

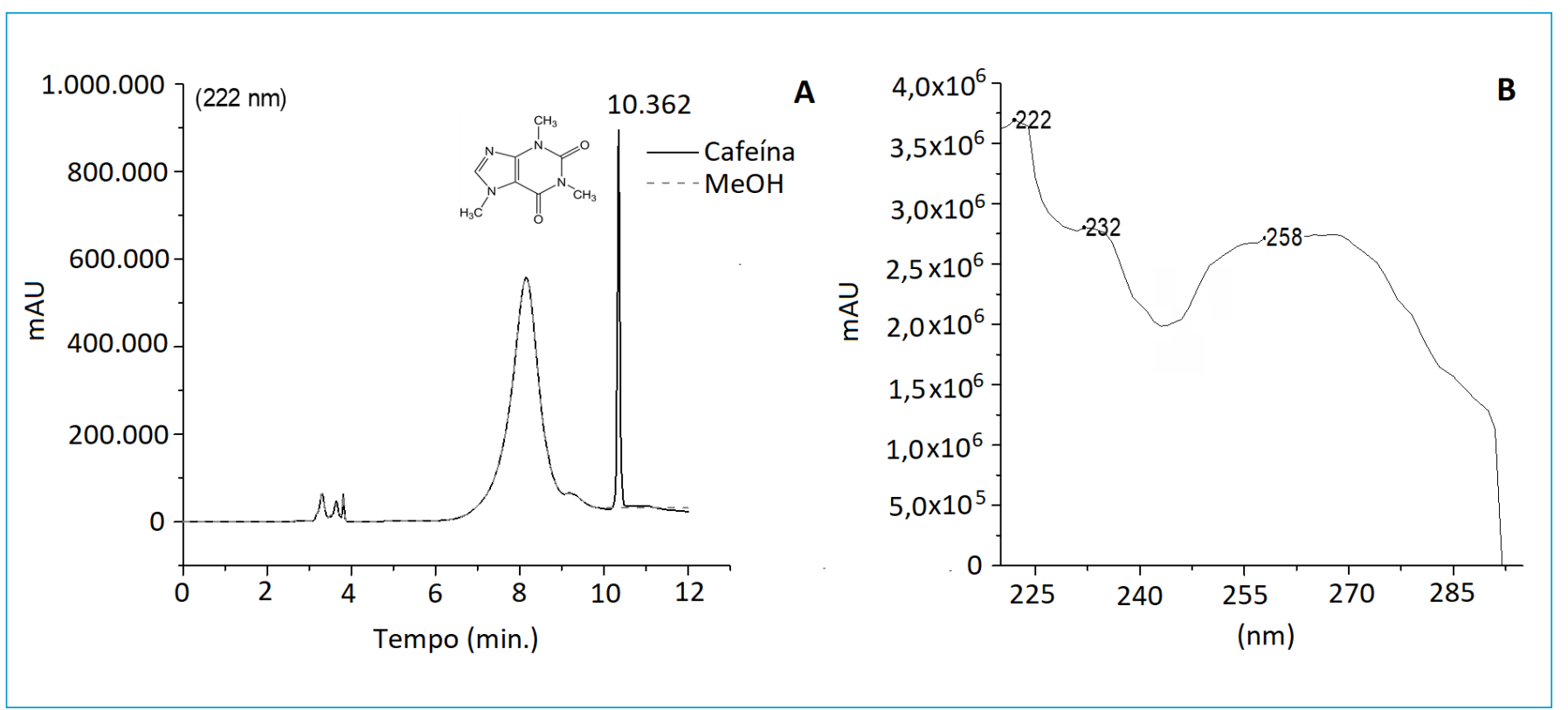

Figura 2 - Perfis (A) cromatográfico e (B) espectrofotométrico da cafeína.

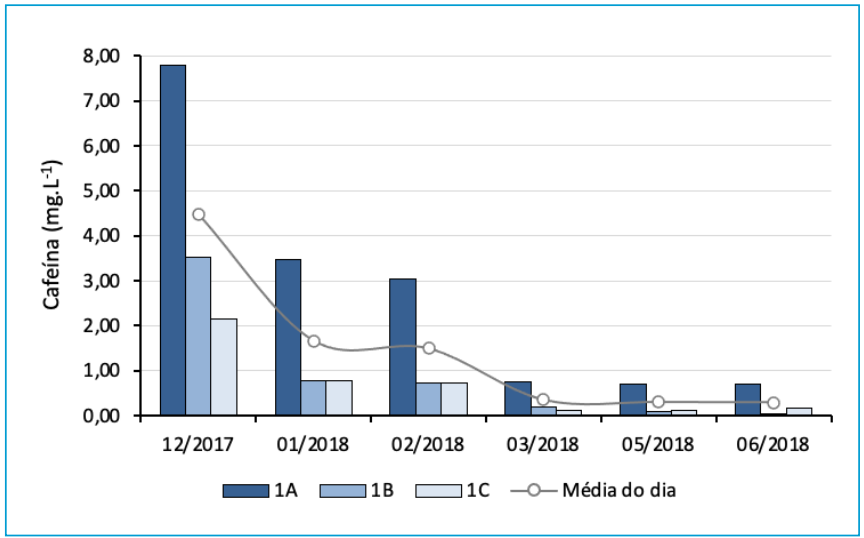

Figura 3 - Variações diária e sazonal da concentração de cafeína no ponto P1 do córrego Sem Nome.

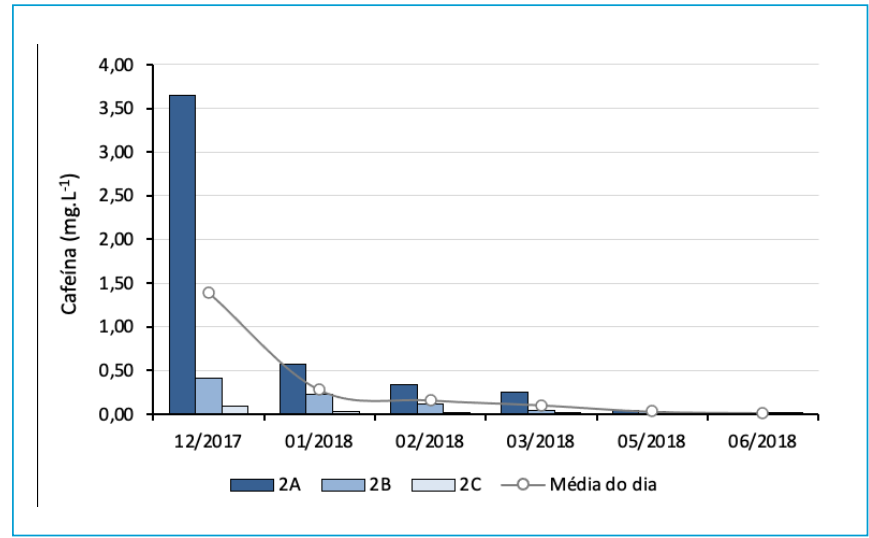

Figura 4 - Variações diária e sazonal da concentração de cafeína no ponto P2 do córrego Sem Nome. 
do Lago Deal (Estados Unidos) em períodos chuvosos, cenário explicado pelo transbordamento de efluentes sanitários.

Aproximadamente $5 \mathrm{~m}$ a montante do ponto $\mathrm{P} 1$ tem uma galeria de drenagem, despejando as águas pluviais e, também, o esgoto doméstico in natura. Não há tempo para que ocorra a dispersão da cafeína ao longo de todo o volume de água, o que justifica as maiores concentrações aferidas no primeiro ponto. Em todos os meses analisados, a parte da manhã foi a mais problemática. No mês de dezembro de 2017, no ponto $\mathrm{P} 2$, entre os períodos da manhã e da noite, a relação encontrada foi de $3.650 \%$, possivelmente em razão do hábito da população de consumir café preferencialmente pela manhã.

No rio Palmital (Bacia do Alto Iguaçu), Ide et al. (2013) encontraram a maior concentração de cafeína $\left(20,13 \mu \mathrm{g}\right.$. $\left.\mathrm{L}^{-1}\right)$ no ponto de amostragem localizado em uma região de moradias irregulares às margens do rio, desprovida de mata ciliar e com o lançamento de esgoto sem nenhum tipo de pré-tratamento. Por outro lado, as menores concentrações (máxima: 8,90 $\left.\mu \mathrm{g} . \mathrm{L}^{-1}\right)$ foram obtidas em uma área menos povoada. Na Baía de Guanabara (Bacia Leopoldina), Ferreira (2005) identificou concentrações de cafeína entre 160 e $357 \mu \mathrm{g} . \mathrm{L}^{-1}$, ressaltando que tais valores indicam, claramente, problemas com a qualidade da água. Gonçalves, Rodrigues e Silva-Filho (2017) avaliaram a presença de cafeína no rio Paquequer (Teresópolis, Rio de Janeiro), obtendo teores entre 0,16 e 47,5 $\mu \mathrm{g} . \mathrm{L}^{-1}$. As menores concentrações foram observadas em uma área de preservação ambiental (Parque Nacional PARNASO). A situação mais crítica foi aferida no local de maior influência antrópica. Os pesquisadores concluíram que, no âmbito nacional, a poluição das águas urbanas envolve principalmente o despejo inadequado de esgoto doméstico e o crescimento demográfico.

Os resultados obtidos para a cafeína confirmaram as hipóteses levantadas nos parâmetros DBO e OD, especialmente sobre a existência de ligações clandestinas em residências da Sub-bacia do Córrego Sem Nome. Por mais que os parâmetros químicos avaliados possam refletir tanto os insumos gerados na bacia de drenagem, provenientes do uso e da ocupação do solo e das atividades antropogênicas, quanto o lançamento de esgoto doméstico clandestino, é difícil afirmar se existe ou não a poluição por esgoto doméstico exclusivamente por tais indicadores. Quando encontrada, em razão da sua procedência, a cafeína indica que houve o lançamento de esgoto doméstico no curso d’água.

\section{CONCLUSÕES}

Foram observados traços de cafeína em todas as amostras. O presente trabalho suporta o seu uso como indicador de poluição por esgoto doméstico em corpos d'água urbanos. Para tais ambientes, ela funciona como uma ferramenta para os gestores ambientais em decorrência da eficiência de seus resultados, uma vez que o seu uso é exclusivamente antrópico.

As variabilidades espacial e temporal dos valores encontrados para os parâmetros analisados estão associadas a diferentes tipos de fontes de poluição em toda a bacia. Por ser um ambiente urbano, o córrego está sendo solicitado mais do que a sua capacidade de resiliência, o que resulta na constante degradação da qualidade de suas águas. Em períodos chuvosos, o OD e a DBO apresentaram concentrações mais próximas do recomendado pela Resolução CONAMA n ${ }^{\circ} 357 / 05$, indicando que a poluição difusa tem menos impacto do que o lançamento de esgoto doméstico por ligações clandestinas no córrego. Por outro lado, a cafeína apresentou as maiores concentrações com a ocorrência de precipitação, relacionadas ao transbordamento e ao vazamento de esgotos domésticos, além das ligações irregulares.

\section{CONTRIBUIÇÕES DOS AUTORES}

Bega, J. M. M.: Conceituação, Curadoria de Dados, Análise Formal, Investigação, Escrita - Primeira Redação, Escrita - Revisão e Edição. Oliveira, J. N.: Conceituação, Obtenção de Financiamento, Administração do Projeto, Supervisão. Albertin, L. L.: Escrita - Revisão e Edição. Isique, W. D.: Análise Formal, Metodologia, Escrita - Revisão e Edição.

\section{REFERÊNCIAS}

ALVARES, C.A.; STAPE, J.L.; SENTELHAS, P.C.; GONÇALVES, J.L.M.; SPAROVEK, G. Köppen's climate classification map for Brazil. Meteorologische Zeitschrift, v. 22, n. 6, p. 711-728, 2013. https://doi.org/10.1127/0941-2948/2013/0507

AMERICAN PUBLIC HEALTH ASSOCIATION (APHA). Standard Methods for the Examination of Water and Wastewater. 23a ed. Washington, D.C.: APHA, 2017.

AMÉRICO, J.H.P. Ocorrência de Compostos Farmacológicos no Córrego da Onça, Município de Três Lagoas - MS. 101f. Dissertação (Mestrado) Faculdade de Engenharia Civil, Universidade Estadual Paulista "Júlio de Mesquita Filho", Ilha Solteira, 2010.

BANERJEE, A.; CHAKRABARTY, M.; RAKSHIT, N.; BHOWMICK, A.R.; RAY, S. Environmental factors as indicators of dissolved oxygen concentrations and zooplankton abundance: Deep learning versus traditional regression approach. Ecological Indicators, v. 100, p. 99-117, 2019. https://doi.org/10.1016/j. ecolind.2018.09.051

BUERGE, I.J; POIGER, T.; MÜLLER, M.D.; BUSER, H-R. Caffeine, an anthropogenic marker for wastewater contamination of surface Waters Environmental Science \& Technology, v. 37, n. 4, p. 691-700, 2003. https:// doi.org/10.1021/esO2O125z

BRASIL. Conselho Nacional do Meio Ambiente (CONAMA). Resolução $n^{\circ}$ 357/05. Estabelece a classificação das águas doces, salobras e salinas do Território Nacional. Brasília: SEMA, 2005.

COMPANHIA AMBIENTAL DO ESTADO DE SÃO PAULO (CETESB). Guia nacional de coleta e preservação de amostras: água, sedimento, 
comunidades aquáticas e efluentes líquidos. São Paulo: CETESB; Brasília: ANA, 2011. 326 p.

ESPEJO, L.; KRETSCHMER, N.; OYARZÚN, J.; MEZA, F.; NÚÑEZ, J.; MATURANA, H.; SOTO, G.; OYARZO, P.; GARRIDO, M.; SUCKEL, F.; AMEZAGA, J.; OYARZÚN, R. Application of water quality indices and analysis of the surface water quality monitoring network in semiarid North-Central Chile. Environmental Monitoring and Assessment, v. 184, n. 9, p. 5571-5588, 2012. https://doi. org/10.1007/s10661-011-2363-5

FERREIRA, A.P. Cafeína como indicador ambiental prospectivo para avaliar ecossistemas aquáticos urbanos. Cadernos de Saúde Pública, v. 21, n. 6, p. 1884-1892, 2005. https://doi.org/10.1590/S0102-311X2005000600038

FERREIRA, A.P.; CUNHA, C.L.N. Anthropic pollution in aquatic environment: development of a caffeine indicator. International Journal of Environmental Health Research, v. 15, n. 4, p. 303-311, 2005. https://doi. org/10.1080/09603120500155898

FIA, R.; TADEU, H.C.; MENEZES, J.P.C.; FIA, F.R.L.; OLIVEIRA, L.F.C. Qualidade da água de um ecossistema lótico urbano. Revista Brasileira de Recursos Hidricos, v. 20, n. 1, p. 267-275, 2015. https://doi.org/10.21168/rbrh.v20n1.p267275

GONÇALVES, E.S.; RODRIGUES, S.V.; SILVA-FILHO, E.V. The use of caffeine as a chemical marker of domestic wastewater contamination in surface waters: seasonal and spatial variations in Teresópolis, Brazil. Ambiente \& Água, v. 12, n. 2, p. 192-202, 2017. https://doi.org/10.4136/ambi-agua.1974

HUKKANEN, J.; JACOB, P.; BENOWITZ, N.L. Metabolism and disposition kinetics of nicotine. Pharmacological Reviews March, v. 57, n. 1, p. 79-115, 2005. https://doi.org/10.1124/pr.57.1.3

IDE, A.H.; CARDOSO, F.D.; SANTOS, M.M.; KRAMER, R.D.; AZEVEDO, J.C.R.; MIZUKAWA, A. Utilização da cafeína como indicador de contaminação por esgotos domésticos na Baía do Alto Iguaçu. Revista Brasileira de Recursos Hidricos, v. 18, n. 2, p. 201-211, 2013. https://doi.org/10.21168/rbrh.v18n2.p201-211

INSTITUTO BRASILEIRO DE GEOGRAFIA E ESTATISTICA (IBGE). Censo demográfico 2010. Diário Oficial da União, Brasília, Seção 1, n. 211, 2010.

KALSCHEUR, K.N.; PENSKAR, R.R.; DALEY, A.D.; PECHAUER, S.M.; KELLY, J.J.; PETERSON, C.G.; GRAY, K.A. Effects of anthropogenic inputs on the organic quality of urbanized streams. Water Research, v. 46, n. 8, p. 2515-2524, 2012. https://doi.org/10.1016/j.watres.2012.01.043

LIU, Y.; BRALTS, V.F.; ENGEL, B.A. Evaluating the effectiveness of management practices on hydrology and water quality at watershed scale with a rainfall runoff model. Science of the Total Environment, v. 511, p. 298209, 2015. https://doi.org/10.1016/j.scitotenv.2014.12.077

LORENZO, T.; SÁNCHEZ, A.C.; MARZIO, W.D.; DONCEL, P.G.; MARTÍNEZ, L.N.; GALASSI, D.M.P.; IEPURE, S. The role of freshwater copepods in the environmental risk assessment of caffeine and propranolol mixtures in the surface water bodies of Spain. Chemosphere, v. 220, p. 227-236, 2019. https://doi.org/10.1016/j.chemosphere.2018.12.117

MADER, M.; SCHMIDT, C.; GELDERN, R.; BARTH, J.A.C. Dissolved oxygen in water and its stable isotope effects: A review. Chemical Geology, v. 473, p. 10-21, 2017. https://doi.org/10.1016/j.chemgeo.2017.10.003

MANDAL, S.; DEBNATH, M.; RAY, S.; GHOSH, P.B.; ROY, M.; RAY, S. Dynamic modelling of dissolved oxygen in the creeks of Sagar island., Hooghly-Matla estuarine system, West Bengal, India. Applied Mathematical Modelling, v. 36, n. 12, p. 5952-5963, 2012. https://doi.org/10.1016/j.apm.2011.10.013

MARTINS, M.L.; PRIMEL, E.G.; CALDAS, S.S.; PRESTES, O.D; ADAIME, M.B.; ZANELLA, R. Microextração Líquido-Líquido Dispersiva (DLLME): fundamentos e aplicações. Scientia Chromatographica, v. 4, n. 1, p. 35-51, 2012. https://doi.org/10.4322/sc.2012.004

MENEZES, J.P.C; BITTENCOURT, R.P.; FARIAS, M.S.; BELLO, I.P.; FIA, R. OLIVEIRA, L.F.C. Relação entre padrões de uso e ocupação do solo e qualidade da água em uma bacia hidrográfica urbana. Engenharia Sanitária e Ambiental, v. 21, n. 3, p. 519-534, 2016. https://doi.org/10.1590/ S1413-41522016145405

ORTEGA, D.J.P.; CARVALHO, S.L. Avaliação dos efeitos das atividades antropóficas nos recursos hídricos na Sub-bacia Hidrográfica do Córrego do Ipê - SP. Revista Brasileira de Recursos Hidricos, v. 18, n. 3, p. 97-108, 2013. https://doi.org/10.21168/rbrh.v18n3.p97-108

PEELER, K.A. Caffeine as an anthropogenic source indicator in freshwater and marine systems. 132f. Tese (Master in Oceanography) - Florida State University, Flórida, 2004.

POLETO, C. Monitoramento e avaliação da qualidade da água em uma microbacia hidrográfica no municipio de Ilha Solteira - SP. 161f. Dissertação (Mestrado) - Faculdade de Engenharia Civil, Universidade Estadual Paulista “Júlio de Mesquita Filho", Ilha Solteira, 2003.

REGAL, K.A.; HOWALD, W.N.; PETER, R.M.; GARTNER, C.A.; KUNZE, K.L. NELSON, S.D. Subnanomolar quantification of caffeine's in vitro metabolites by stable isotope dilution gas chromatography-mass spectrometry. Journal of Chromatography, v. 708, n. 1-2, p. 75-85, 1998. https://doi.org/10.1016/ s0378-4347(97)00656-7

ROSEMOND, S.; DURO, D.C.; DUBÉ, M. Comparative analysis of regional water quality in Canada using the Water Quality Index. Environmental Monitoring and Assessment, v. 156, n. 1-4, p. 223-240, 2009. https://doi. org/10.1007/s10661-008-0480-6

SALLAM, G.A.H.; ELSAYED, E.A. Estimating relations between temperature, relative humidity as independent variables and selected water quality parameters in Lake Manzala, Egypt. Ain Shams Engineering Journal, v. 9, n. 1, p. 1-14, 2018. https://doi.org/10.1016/j.asej.2015.10.002

SANKARARAMAKRISHNAN, N.; GUO, Q. Chemical tracers as indicator of human fecal coliforms at storm water outfalls. Environment International, v. 31, n. 8, p. 1133-1140, 2005. https://doi.org/10.1016/j.envint.2005.04.002

SANTIM, T.G.S. Uso de geotecnologias na análise temporal dos impactos da urbanização na sub-bacia do Córrego Sem Nome em Ilha Solteira/SP 228f. Dissertação (Mestrado) - Faculdade de Engenharia Civil, Universidade Estadual Paulista "Júlio de Mesquita Filho", Ilha Solteira, 2010.

SAUVÉ, S.; ABOULFADL, K.; DORNER, S.; PAYMENT, P.; DESCHAMPS, G. PRÉVOST, M. Fecal coliforms, caffeine and carbamazepine in stormwater collection systems in a large urban area. Chemosphere, v. 86, n. 2, p. 118-123, 2012. https://doi.org/10.1016/j.chemosphere.2011.09.033

SENTA, I.; GRACIA-LOR, E.; BORSOTTI, A.; ZUCCATO, E.; CASTIGLIONI, S. Wastewater analysis to monitor use of caffeine and nicotine and evaluation of their metabolites as biomarkers for population size assessment. Water Research, v. 74, p. 23-33, 2015. https://doi.org/10.1016/j.watres.2015.02.002

SRDJENOVIC, B.; DJORDJEVIC-MILIC, V.; GRULIC, N.; INJAC, R.; LEPOJEVIC, Z. Simultaneous HPLC determination of caffeine, theobromine, 
and theophylline in food, drinks, and herbal products. Journal of Chromatographic Science, v. 46, n. 2, p. 144-149, 2008. https://doi.org/10.1093/ chromsci/46.2.144

TONG, S.T.Y; CHEN, W. Modeling the relationship between land use and surface water quality. Journal of Environmental Management, v. 66 , n. 4, p. 377-393, 2002. https://doi.org/10.1006/jema.2002. 0593
ZAMBRANO, K.T.; MARANGONI, T.T.; OLIVEIRA, J.N.; SANTINI JUNIOR, M.A.; FELIZARDO, L.M. Avaliação temporal da qualidade da água de um rio urbano: estudo de caso do Córrego Sem Nome em Ilha Solteira - SP. In: CONGRESSO ABES/FENASAN. Anais [...]. São Paulo, 2017.

ZAMBRANO, K.T.; POLETO, C.; OLIVEIRA, J.N. A comparative analysis on water quality in an urban watershed Management of Environmental Quality, v. 28, n. 4, p. 566-578, 2017. https://doi.org/101108/MEQ-07-2015-0141 